\title{
ASPECTOS ADMINISTRATIVOS DEL REGIMEN PROTECTOR DE LOS CONSUMIDORES Y USUARIOS
}

\author{
por \\ José A. López Pellicer \\ Doctor en Derecho \\ Secretario de 1." categoria de Administración Local, Diplomado
}

SUMARIO: I. INTRODUCCION.-II. CONSTITUCIONALIZACION DE LA POLITICA PROTECTORA. NORMATIVA REGULADORA.-III. ORGANIZACION ADMINISTRATIVA Y PARTICIPACION DE LOS INTERESADOS: 1. ADMINISTRACIÓN DEL ESTADO. 2. Comunidades Autónomas. 3. Administración Local. 4. InstituCIONALIZACIÓN JURÍDICA DE LA PARTICIPACIÓN DE LOS COSUMIDORES Y USUARIOS.-IV. FUNCIONES ADMINISTRATIVAS: 1. Policía administrativa. 2. SeRvicio público. 3. Acciones de fomento.V. CONCLUSIONES.

\section{INTRODUCCION}

El tema de la protección o defensa de los consumidores de bienes y de los usuarios de servicios ha obtenido en los últimos años -sobre todo a partir de la aplicación de la política de desarrollo económico en la década de los años sesenta - un generalizado y, desde entonces, creciente interés. Los desequilibrios en el aspecto económico, entre la producción y suministro de bienes y servicios en relación con el consumo, antaño limitados por las propias condiciones de un reducido mercado, se han visto agudizados en la actual sociedad y economía de consumo de masas. Ante una situación eco- 
nómica en que productores y distribuidores ostentan, de hecho, poder y capacidad para determinar e influir decisivamente en las condiciones de mercado, no ha de extrañar, pues, primero, que como natural reacción, los consumidores se preocupen de la calidad y fiabilidad de los productos —alimentos, vestido, servicios, etc.que demanda y adquiere para satisfacer sus varias necesidades; y después, que, cabalmente por ello, como mecanismo de «autodefensa" social, para la protección de sus intereses, económicos, sanitarios, etc., se hayan agrupado y se integran en diversas asociaciones, a fin de equilibrar mediante una acción conjunta y a modo de "poder compensador", su posición, ante los posibles abusos que, de la situación de predominio e influencia en el mercado, sobre todo de las grandes empresas productoras y distribuidoras de bienes de consumo, pueden derivarse.

El interés general o colectivo que el propio consumo de masas hoy entraña, no ya sólo cuantitativa sino también cualitativamente, determina que, junto a esa posición de defensa asociada que asumen los propios consumidores y usuarios, los poderes públicos -el Estado, los Municipios, también hoy las Comunidades Autónomashayan iniciado y desarrollen asimismo una acción protectora de los intereses implicados desde el punto de vista colectivo en el consumo, mediante la creación de una ordenación legal y la instrumentación complementaria de una estructura administrativa que encauce y haga operativa la acción administrativa en esta materia. El punto de inflexión determinante de esta acción pública orientada a la protección de los consumidores, en nuestro país, se halla en el artículo 51 de la Constitución de 1978, en que se atribuye a los poderes públicos la función de garantizar la defensa de los consumidores y usuarios, protegiendo mediante procedimientos eficaces la seguridad, la salud y los legítimos intereses económicos de los mismos; así como las funciones de promover la información y educación de aquéllos, fomentar sus organizaciones y oír a éstas en las cuestiones que puedan afectarles, remitiendo a los términos que la Ley establezca.

No cabe desconocer, en fin, la importancia del esfuerzo y el apoyo que ciertos organismos internacionales, como la OCDE, vienen dedicando a esta cuestión. El Comité de Política de los Consumidores de este organismo hace especial hincapié, entre otros objetivos, en la «información y educación de los consumidores" y en una "protección eficaz contra los riesgos susceptibles de afectar a 
la salud, seguridad e intereses económicos de los mismos». De modo análogo, la Carta de Protección a los Consumidores aprobada por el Consejo de Europa, a través de su Asamblea consultiva (mayo de 1973) y las resoluciones de 14 de abril de 1975 y 19 de mayo de 1981 del Consejo de Ministros de la Comunidad Económica Europea (1), para una política de protección e información de los consumidores, que implica la defensa de la salud, la seguridad y los intereses económicos de éstos, constituyen un antecedente y obligada referencia a tener en cuenta en razón al influjo que esta normativa comunitaria ha tenido en la elaboración del citado texto constitucional y ante la exigencia de homologar la normativa juridica y administrativa en la materia, que ha de producirse en el futuro inmediato si se cumple la previsible incorporación de nuestro país a la Comunidad.

\section{CONSTITUCIONALIZACION DE LA POLITICA PROTECTORA. NORMATIVA REGULADORA}

Sin precedentes en el ordenamiento constitucional español, el artículo 51 citado (2) sienta, dentro de los «principios rectores de la política social y económica», recogidos en el Capítulo III del

(1) Vid. Bando CASADo, H. C.: «La protección del consumidor en Europa: dimensión jurídico-comparada del artículo 51 de la Constitución», en Estudios Homenaje al Profesor Garcia Trevijano, Madrid, 1982, pág. 31 y sigs. Considera este autor, con referencia a la primera resolución cit., que, aunque la afirmación que hace de que «la mejora cualitativa de las condiciones de vida es una de las misiones de la Comunidad Económica, que implica la protección de la salud, de la seguridad y de los intereses económicos del consumidor" no tiene un entronque directo con el Tratado de Roma, es necesario tener en cuenta que, en virtud del artículo 2 del mismo Tratado, la CEE tiene como fin la protección de un desarrollo armonioso de las actividades económicas en el conjunto de la Comunidad, una expansión continua y equilibrada y un incremento constante del nivel de vida. La resolución de 19 de mayo de 1981, referida a un segundo programa de la CEE, tiende a situar al consumidor en orden a poder ejercer los cinco derechos fundamentales siguientes: El de la protección de su salud y de su seguridad, el de los intereses económicos, a la reparación de los daños, a la información y a la educación y a la representación. Vid. asimismo SEQUEIRA MARTín, A. J.: "Defensa del consumidor y Derecho Constitucional económicon, Rev. Esp. Derecho Constitucional, núm. 10 (1984), pág. 103 y siguientes.

(2) Que tiene como precedente el artículo $81 . \mathrm{m}$ ) de la Constitución Portuguesa de 1976, según el cual "corresponde prioritariamente al Estado: Proteger al consumidor, especialmente mediante el apoyo a la creación de cooperativas y de asociaciones de consumidoresn (vid. CAzORLa Prieto, en Comentarios a la Constitución, dirigidos por Garrido Falla, F., Edit. Civitas, Madrid, 1980, pág. 562). El citado precepto constitucional también se ha inspirado en la resolución comunitaria de 14 de abril de 1975, cit. en la nota anterior. 
Título I del Texto constitucional, los criterios básicos que han de inspirar la normativa y la actuación de los poderes públicos en orden a garantizar la protección de los intereses de los consumidores.

El citado precepto constitucional recoge a este objeto como derechos fundamentales de los consumidores y usuarios los relativos a la seguridad y a la salud (derecho este último asimismo reconocido en el art. 43.2 de la Constitución), así como el derecho a la protección de sus legítimos intereses económicos (en estrecha conexión este aspecto con el precepto del artículo 24.1, del propio texto constitucional). Para asegurar la defensa de estos derechos básicos, se complementan los mismos con otros, en cierto modo instrumentales, en cuanto ordenados a la efectiva realización o ejercicio de los indicados, que son los derechos de «información y educación de los consumidores y usuarios», para que éstos puedan conocer las características y condiciones de los diferentes bienes y servicios, así como el modo de realizar su adecuada utilización o consumo; y en último término, se garantiza, con el mismo sentido instrumental, el derecho a la participación o representación, esto es, el derecho a organizarse y a ser oído, en todos aquellos asuntos o cuestiones que puedan afectarles.

Se articula, en suma, en nuestro texto fundamental, un conjunto de derechos que tienen por objeto salvaguardar, dentro del proceso de la actividad económica, los intereses de los demandantesconsumidores de bienes y servicios, a fin de superar o corregir situaciones de indefensión y los abusos a que en una posición de inferioridad y debilidad, los mismos, en no pocas ocasiones, se han visto o se ven sometidos (3).

(3) La oferta de los bienes de consumo en su más amplia gama, está cada vez más en manos de grandes sociedades, con mucha frecuencia multinacionales, que desde sus posiciones privilegiadas imponen su ley y conveniencia en el mercado y formalizan sus relaciones jurídicas con los consumidores por la vía del contrato de adhesión. En él el demandante-consumidor acepta o no el bloque de las cláusulas previamente fijadas por el oferente, sin posibilidad de modificación alguna. La indefensión del consumidor y los abusos cometidos con él han llegado así a situaciones insospechables. Pero ahi no acaba todo. Los circuitos comerciales y la organización económico-social de nuestros días han impuesto un tremendo alejamiento, sobre todo en el sector alimenticio, aunque también en otros muchos, del productor o generador de los bienes de consumo del consumidor. Este alejamiento ha dado enormes posibilidades a las irregularidades, no sólo en el campo de los precios sino también en el de la calidad de los productos de consumo, de lo que el principal perjudicado es el consumidor (CAZORLA Prieto, cit. en nota anterior, página 561 y sigs.). Vid. asimismo, Bermejo VerA, J.: "Aspectos jurídicos de la pro. tección del consumidor», Rev. de Administración Pública, núm. 87, pág. 255 y sigs. 
El reconocimiento y la garantía constitucional de los referidos derechos - básicos e instrumentales - se completa, en el apartado $3 .^{\circ}$ del artículo 51 del texto constitucional, con la reserva a la ley de la regulación del «comercio interior y el régimen de autorización de productos comerciales"; con lo que se persigue superar la situación hasta ahora existente de diversas regulaciones parciales y esporádicas en esta materia. Se trata de evitar - dice BERMEJo VERA (4) - la hasta ahora frecuente tendencia a la normativización coyuntural y por cauces casi exclusivamente administrativos, que ha propiciado cierto desbarajuste caprichoso en las políticas de intervención del poder público en la vida económica y, por lo que ahora nos importa, si bien ha conseguido formulaciones esporádicas en el ámbito de la tutela del consumidor, también es cierto que ha dificultado muy sensiblemente la utilización efectiva de los instrumentos, técnicas o mecanismos teóricamente dispuestos para la defensa o protección de los consumidores.

En desarrollo del citado precepto constitucional e inspirándose asimismo en las normas y directrices vigentes en la materia en la Comunidad Económica Europea, la Ley 26/1984, de 19 de julio, de Defensa de los Consumidores y Usuarios (5), concreta sus objetivos en

- establecer, sobre bases firmes y directas, los procedimientos eficaces para la defensa de los consumidores y usuarios;

- disponer del marco legal adecuado para favorecer un desarrollo óptimo del movimiento asociativo en este campo; y

- declarar los principios, criterios, obligaciones y derechos que configuran la defensa de los consumidores y usuarios y que, en el ámbito de sus competencias, habrán de ser tenidos en cuenta por los poderes públicos en las actuaciones y desarrollos normativos futuros en el marco de la doctrina sentada por el Tribunal Constitucional (6).

(4) En el estudio cit. en nota anterior, Rev. de Admón. Pública, núm. 87, página 261 y sigs.

(5) Que no excluye ni suplanta - dice en su breve exposición de motivos- otras actuaciones y desarrollos normativos derivados de ámbitos competenciales cercanos o conexos, tales como la legislación mercantil, penal y procesal y las normas sobre seguridad industrial, higiene y salud pública, ordenación de la producción y comercio interior.

(6) Vid. la Sentencia número 71/1982, de 30 de noviembre, del Tribunal Constitucional, en relación con el Estatuto del Consumidor del País Vasco (BOE 29-12-82), y la Sentencia número 32/1983, de 28 de abril (BOE 17-5-83), en relación con el Real Decreto 2824/1981, de 27 de noviembre, sobre coordinación sanitaria, y con el Real Decreto 2825/1981, de la misma fecha, sobre registro sanitario de alimentos. 
La Ley 26/1984, establece que la defensa de los consumidores y usuarios se hará, en todo caso, en el marco del sistema económico diseñado en los artículos 38 y 128 de la Constitución y con sujeción asimismo a lo establecido en el artículo 139 (7). Lo que como es lógico, presupone la libertad de empresa y, dentro del marco constitucional económico, asimismo, el reconocimiento de la iniciativa pública en la actividad económica; sin perjuicio en ningún caso de la unidad del orden económico - y por ende, del principio de unidad del mercado- en todo el ámbito del Estado. Principios y exigencias todas ellas que, es sabido, básicamente definen la denominada "constitución económica" en nuestro ordenamiento (8), en cuyo modelo la protección del consumidor trata, por ello, de asegurarse mediante la articulación, como se verá después, de un conjunto de mecanismos jurídicos y asociativos de diversa naturaleza.

A efecto de delimitar, por lo demás, el ámbito de aplicación de dicha Ley y, en definitiva, el ámbito de protección de los indicados derechos, se define a los consumidores y usuarios como «las personas físicas o jurídicas que adquieren, utilizan o disfrutan como destinatarios finales, bienes muebles o inmuebles, productos, servicios, actividades o funciones, cualquiera que sea la naturaleza pública o privada, individual o colectiva de quienes los producen, facilitan, suministran o expiden (9).

Se da, pues, un amplio concepto de consumidor y de usuario que engloba, en estas dos figuras, no sólo al individuo particular, sino también las personas jurídicas o entidades - de cualquier naturaleza- que adquieren bienes o utilizan servicios o funciones de cualquier clase, con una especificación que matiza su posición en el proceso económico: Que aparezca situada como «destinatario final» en la posición de demanda para el consumo o uso inmediato del producto o servicio, el sujeto o persona que actúe en aquella posición económica y jurídica. Esto, como es lógico, excluye del

(7) Cfr. el artículo $10^{\circ}$, número 2 , de la Ley cit., en relación con los artículos 51 , 53.3, 38, 128 y 139 de la Constitución vigente.

(8) Vid. Garrido Falla, F.: «El modelo económico en la Constitución y la revisión del concepto de servicio público», Rev. Española de Derecho Administrativo, Civitas, núm. 29 (1981), pág. 225 y sigs. Asimismo, del propio autor, con ArIÑo OrTIz y otros: El modelo económico de la Constitución Española, Estudios Económicos, 1981. Sobre el artículo 139 de la Constitución, asimismo la Sentencia del Tribunal Constitucional número 96/1984, de 19 de octubre (BOE del 31 del mismo mes).

(9) Artículo $1 .^{\circ}$, número 2, de la Ley 26/1984, de 19 de julio. Sobre el concepto de consumidor como sujeto de derecho, vid., por todos, BERMEJo VERA, J., cit. en nota 3, Rev. de Administración Pública, núm. 87, pág. 258 y sigs. 
concepto legal a los intermediarios intervinientes en el proceso de comercialización (10); pero es independiente, en fin, del carácter de los sujetos situados en la posición de la oferta -producción, comercio-, que incluye, por tanto, asimismo, no sólo a las empresas o personas privadas sino incluso a las públicas.

Referido a este aspecto subjetivo el ámbito de la Ley 26/1984 («a los efectos de esta Ley», dice su art. 1., núm. 2), mantiene en consecuencia toda su virtualidad la protección jurídica del consumidor prevista y regulada en otros sectores o ramas de nuestro ordenamiento jurídico. Así, en el orden jurídico-penal, responde a una ratio tuitiva o protectora de personas que pueden incluirse en un concepto lato de consumidor, la tipificación como delitos de conductas perjudiciales para la salud pública (11), las llamadas maquinaciones para alterar el precio de las cosas tipificadas en el artículo 540 y siguientes del Código Penal, etc.; cuyos tipos delictivos pueden concurrir además, en su caso, con el delito de estafa y con los de homicidio o lesiones, cuando la alteración produjere alguna de estas consecuencias.

En el ordenamiento jurídico privado, es sabido que, en materia de contratación, el consumidor adquirente de un objeto o cosa con error sobre la materia, la identidad o cualidad de la misma, puede instar civilmente la nulidad del contrato por vicio en el consentimiento (arg. art. 1.265 del Código Civil); y el vendedor de una cosa está obligado al saneamiento por defectos o gravámenes ocultos de la cosa vendida (art. 1.484 y sigs. del propio texto legal civil); normativa cuya aplicabilidad no cabe desconocer, dado el significado que como régimen general de Derecho común tiene, a salvo de lo dispuesto en el Código de Comercio y leyes especiales aplicables a los contratos mercantiles (12). Por ello, el artículo $7 .^{\circ}$ de la Ley $26 / 1984$, de 19 de julio, prevé en orden a la protección de los legítimos intereses económicos y sociales de los consumidores y

(10) Artículo $10^{\circ}$, número 3, de la Ley 26/1984: No tendrán la consideración de consumidores o usuarios quienes, sin constituirse en destinatarios finales, adquieran, almacenen, utilicen o consuman bienes o servicios con el fin de integrarlos en procesos de producción, transformación, comercialización o prestación a terceros.

(11) Cfr. el artíulo 341 y sigs. del vigente Código Penal, en especial el artículo 346, según la redacción dada por la Ley Orgánica 3/1983, de 25 de junio.

(12) BERMEjo VerA, J., est. cit. en nota 3, pág. 278 y sigs. En el ordenamiento vigente, cfr. los artículos 336, 344 y 345 del Código de Comercio. Asimismo, la Ley de 17 de julio de 1965, reguladora de las ventas a plazos de bienes muebles, y el Decreto 1193/1966, de 12 de mayo, por el que se dictan disposiciones complementarias a la Ley anterior. 
usuarios, la aplicación, además, de lo previsto en las normas civiles y mercantiles.

\section{ORGANIZACION ADMINISTRATIVA Y PARTICIPACION DE LOS INTERESADOS}

Promover y desarrollar la protección y defensa de los consumidores y usuarios constituye una competencia atribuida a los poderes públicos $\mathrm{y}$, en concreto, a las Administraciones Públicas territoriales, por la Ley $26 / 1984$, de 19 de julio, que reparte los diversos aspectos materiales de la competencia entre la Administración del Estado (art. 39), de las Comunidades Autónomas (art. 40) y las Entidades Locales (art. 41); cuyas funciones ofrecen múltiples modalidades, reconducibles, no obstante, en términos generales, a las clásicas actividades de policía administrativa, prestaciones de servicio público y fomento o estímulo de organizaciones y actuaciones particulares que, por su trascendencia comunitaria, se consideran de interés general y que justifican como vamos a ver, incluso, la institucionalización en esta materia del principio de participación ciudadana.

\section{Administración DEl Estado}

En lo que se refiere a la Administración del Estado, la protección del consumo cuenta con enclaves orgánicos en casi todos los ministerios civiles (13). Sin embargo, esta acción se polariza en la actualidad con preferencia, en el Ministerio de Sanidad y Consumo (14), al que, en el aspecto que interesa destacar, compete dirigir las actividades de inspección de fraudes de bienes y servicios susceptibles de consumo y utilización en el mercado nacional, en colaboración con los demás departamentos sectoriales competentes, así como la realización de análisis, pruebas y ensayos de productos en los laboratorios adscritos y la autorización de centros privados para la consecución de aquéllos.

(13) Zabalza Ramos, R.: «Estructuras de la Administración Central para la defensa del consumidor en Españan, Rev. Documentación Administrativa, núm. 136, página 51. BERMEJo VERA, J., cit., pág. 189.

(14) Departamento creado por RD $2823 / 1981$, de 27 de noviembre, modificado por RD-ley 22/1982, de 7 de diciembre. 
En el aspecto orgánico, además de la Subsecretaría de Sanidad y Consumo - de la que dependen la Dirección General de Salud Pública y la de Farmacia y Medicamentos-, dicho Departamento cuenta con un órgano superior más específico en la materia, la Secretaría General para el Consumo, a la que asimismo se atribuye el rango de Subsecretaría (art. 5..$^{\circ}$ núm. 14, del RD Ley 22/1982, de 7 de diciembre), de la que dependen la Dirección General de Inspección del Consumo y la de Control y Análisis de Calidad.

Como organismo autónomo adscrito al propio Ministerio, a través de la Secretaría para el Consumo, existe el Instituto Nacional del Consumo, con la organización y funciones fijadas en el RD 2924/1981, de 4 de diciembre (15).

Ahora bien, sin perjuicio de las específicas competencias de los órganos e instituciones adscritos a Sanidad y Consumo, cuentan asimismo con órganos de defensa de los consumidores y usuarios, otros departamentos como son los de:

- Agricultura, Pesca y Alimentación (16), a través sobre todo de la Subsecretaría de la misma denominación —en que se integran la Dirección General de Industrias Agrarias y Alimentarias y la Dirección General de Política Alimentaria-, y el Servicio Nacional de Productos Agrarios; organización a través de la que el departamento desarrolla sus funciones en la materia, con especial incidencia en lo que se refiere a la normalización y tipificación de productos agrarios y alimenticios, así como la vigilancia de los mercados de origen.

- El Ministerio de Industria y Energía (17), con funciones específicas en materia de distribución, transformación y consumo de las diversas formas de energía y sus fuentes.

- El Ministerio de Economía y Hacienda, del que depende la Secretaría de Estado de Comercio (18), a que compete en este as-

(15) Que mantiene las funciones que a dicho Instituto atribuye el artículo 15.2, del RD 300/1978, de 2 de marzo. Creado el Instituto como «servicio público centralizadon por Decreto 2950/1975, de 7 de noviembre, se transformó en organismo autónomo por RD $3162 / 1977$, de 11 de noviembre.

(16) Denominación dada por el citado RD 2823/1981, y cuya estructura regula el RD 2924/1981, de 4 de diciembre, normativa modificada asimismo por el RD-ley 22/1982, de 7 de diciembre.

(17) Cuya estructura orgánica determina el RD 1613/1979, de 29 de junio; modificado por el $2183 / 1980$, de 10 de octubre y el 2924/1981, de 14 de diciembre, así como el RD-ley 22/1982, de 7 de diciembre, cit.

(18) RD-ley 22/1982, de 7 de diciembre (art. 5. , núm. 4). 
pecto, proponer y ejecutar la política comercial del Gobierno y la regulación y el fomento del comercio interior.

Asimismo depende de este Departamento el Consejo de Defensa de la Competencia, aunque esta materia, regulada por la Ley de represión de prácticas restrictivas de la competencia de 20 de julio de 1963, ha sido considerada más bien como defensora de un cierto orden económico ligado a la corriente «desarrollista» del momento en que fue aprobada (19).

El Instituto de Reforma de las Estructuras Comerciales (IRESCO), organismo autónomo que asimismo venía adscrito al Ministerio de Economía, ha sido suprimido por la Ley 50/1984, de 30 de diciembre, aprobatoria de los presupuestos generales del Estado para 1985 (20).

- Al Ministerio de Transportes, Turismo y Comunicaciones (21) corresponde el ejercicio de la actividad administrativa en materia de transportes terrestres, marítimos y aéreos; comunicaciones postales, telegráficas, telefónicas, etc., así como el control del cumplimiento de las normas reguladoras de las empresas y entidades dedicadas a actividades turísticas.

\section{Comunidades Autónomas}

La nueva estructura territorial de los poderes públicos introducida con el nuevo esquema constitucional y la subsiguiente constitución de las Comunidades Autónomas, ha venido a incidir, como no podía menos de suceder, en esta materia, como en otras. Aun cuando la Constitución de 1978 no es, a este respecto, muy explícita, su artículo 148.1, número 12, admite que las Comunidades Autónomas pueden asumir competencias en materia de "ferias interiores», aun cuando algunos Estatutos de autonomía de Comunidades de régimen gradual o diferido han asumido competencias en materia de comercio interior y, ligadas a ella, para la defensa de los consu-

(19) Vid. Bermejo VerA, J., cit., pág. 282 y sigs. Aunque el preámbulo de la indicada Ley alude, sin embargo, al aindeclinable y permanente deber del Estado de defender al consumidor contra los abusos derivados de restricciones intencionadas a la competencian.

(20) Artículo 85, número 4, apartado $d$ ).

(21) Denominación dada por el $\mathrm{RD} 325 / 81$, de 6 de marzo (art. 18) y cuya organización y funciones precisa el RD 615/78, de 30 de marzo, modificado por otros posteriores, entre los que destaca el RD 425/80, de 8 de febrero, y el RD-ley 22/1982, de 7 de diciembre (art. 5.', núm. 11). 
midores; concepto más amplio a aquél, que quizá encuentra apoyo constitucional en la referencia que al «fomento del desarrollo económico de la Comunidad Autónoma dentro de los objetivos marcados por la política económica nacional» contiene el mismo precepto constitucional en su apartado 13 (22).

La Ley 26/1984, de 19 de julio, en su artículo 40, presupone el régimen autonómico, al decir que corresponderá a las Comunidades Autónomas promover y desarrollar la protección y defensa de los consumidores o usuarios, de acuerdo con lo establecido en sus respectivos Estatutos y, en su caso, en las correspondientes Leyes Orgánicas complementarias de transferencia de competencias.

En términos generales, a la vista de los diversos Estatutos de autonomía, no sólo las Comunidades Autónomas con autonomía plena, sino también las de autonomía gradual o diferida, han recibido, en virtud de sus respectivos Estatutos, competencias en materia de defensa de los consumidores, aunque con diverso alcance, ya que mientras las primeras las han recibido con carácter «exclusivo", aunque sin perjuicio como es lógico de los límites derivados de la ordenación económica general del Estado (23), en cambio las competencias estatutarias atribuidas en la materia a las Comunidades del segundo tipo son meramente ejecutivas, normalmente, y sometidas por tanto a la legislación y reglamentación estatal. Así, entre estas últimas, la Comunidad Autónoma de la Región de Murcia tiene atribuida, en materia de comercio interior y defensa de los consumidores, competencia en orden a la función ejecutiva en los términos que establezcan las leyes y las normas reglamentarias que en desarrollo de su legislación dicte el Estado (24).

En consecuencia, mientras que las primeras Comunidades han asumido competencias legislativas en la materia que tratamos - si bien con los límites generales derivados de los artículos 138 y 139 de la Constitución, entre otros-, las Comunidades con autonomía gradual carecen de poderes de esta naturaleza y alcance, que se

(22) Vid. sobre esta cuestión, de modo general, MuÑoz Machapo, S.: Derecho público de las Comunidades Autónomas, I, Ed. Civitas, Madrid, 1982, (pág. 545 y sigs.).

(23) Así, vid. el artículo 12.1.5 del Estatuto de Autonomía de Cataluña; el artículo 10, número 28, del Estatuto Vasco; el artículo 30, número 4, del Estatuto de Galicia y el artículo 18, número 6, del Estatuto de Andalucía.

(24) Artículo 12.1.i) del Estatuto de Autonomía de Murcia, aprobado por Ley Orgánica 4/1982, de 9 de junio. Id., en el Estatuto de Autonomía de Cantabria, artículo 24.d); La Rioja, artículo 10.1.4.; Castilla-La Mancha, artículo 33.2; Extremadura, artículo 9.4 ; etc. 
limita sólo a competencias para realizar funciones de mera ejecución o gestión administrativa en la materia. Lo que matiza, pues, el ámbito de las funciones a que, de modo genérico, alude el artículo 40 de la referida Ley 26/1984, que, no obstante, deja a salvo la posibilidad de atribución de otras competencias al amparo del artículo 148.2 de la Constitución, o bien por vía extra-estatutaria, al amparo del artículo 150.1 y 2 , del propio texto constitucional.

\section{ADMINISTRACION LOCAL}

La Administración Local y en concreto, la municipal, como organización más próxima a los intereses y necesidades de los administrados, es la que cuenta además con el apoyo de una tradición y continuada experiencia, ofreciendo en consecuencia mayores posibilidades reales de intervenir de manera efectiva e inmediata en orden a la protección de aquéllos, en cuanto consumidores de bienes y usuarios de servicios.

a) La atribución a los Municipios de competencias para intervenir en materia de abastecimientos y, en general, para realizar un conjunto de servicios y funciones públicas vitales para el ciudadano -mercados, mataderos, saneamiento, etc. (25)-, constituye, en efecto, una constante en nuestro régimen administrativo. En e] ordenamiento actual, el Reglamento de Servicios de las Corpora. ciones Locales determina, en su artículo 1..$^{\circ}$, que los Ayuntamientos podrán intervenir la actividad de sus administrados ...en materia de subsistencias, para asegurar el abasto de los artículos de consumo de primera necesidad, la calidad de los ofrecidos en venta, la fidelidad en el despacho de los que se expendan a peso o medida, la normalidad de los precios y la libre competencia entre los suministradores y vendedores. Lo que se completa con la exigencia de que la intervención municipal en esta materia ha de dirigirse - según determina el propio Reglamento en su artículo 18- a asegurar la libre competencia como medio de procurar la economía y los precios; a cuyo efecto los Ayuntamientos sancionarán cualesquiera

(25) Cfr. los artículos 101.c), d) y e), 102 y 103 de la vigente Ley de Régimen Local, texto articulado y refundido de 24 de junio de 1955 . Sobre la competencia municipal, desde una perspectiva histórica y en el ordenamiento actual, vid., en general, MARTIN RETORTILLO, S. y otros: Descentralización administrativa y organización politica, Ed. Alfaguara, Madrid, 1973. 
formas de actuación encaminadas a impedir o dificultar la libertad de tráfico (26).

El proyecto de Ley reguladora de las Bases del Régimen Local, pendiente de aprobación parlamentaria, asume la tradición municipal en la materia, que actualiza de acuerdo con las modernas orientaciones, al determinar como competencia municipal la defensa de usuarios y consumidores [art. 25.2, apartado $g$ )]. Lo que se completa con la función municipal protectora de la salubridad pública [apartado $h$ )], en especial el control de las condiciones sanitarias de toda clase y alimentos y bebidas, y la policía sanitaria en las vías públicas $\mathrm{y}$ en los locales y establecimientos destinados al público; así como con la diversidad de servicios y funciones públicas que los propios Municipios han de gestionar en materia de urbanismo y vivienda, transportes, etc., que asimismo se incluyen en el ámbito de la competencia municipal según el citado precepto.

b) En la ordenación sectorial de la materia, la Ley 26/1984, de 19 de julio, atribuye, en su artículo 41, a las Corporaciones Locales, competencia para "promover y desarrollar la protección y defensa de los consumidores y usuarios en el ámbito de sus competencias y de acuerdo con la legislación estatal y, en su caso, de las Comunidades Autónomas", especialmente en lo que se refiere a los aspectos de información y gestión, inspección de productos y servicios ("para comprobar su origen e identidad, el cumplimiento de la normativa vigente en materia de precios, etiquetado, presentación y publicidad y los demás requisitos o signos externos que hacen referencia a sus condiciones de higiene, sanidad y seguridad»), inspección técnica y sanitaria, y apoyo a las asociaciones de consumidores y usuarios.

c) Por lo demás, para la realización de sus funciones, las Corporaciones Locales pueden contar con el apoyo de la Administración del Estado, especialmente en lo que se refiere a la realización de inspecciones técnicas y sanitarias, y para adoptar las medidas urgentes y requerir las colaboraciones precisas en los supuestos de

(26) Asimismo, en ejercicio de funciones de policía administrativa, los Municipios están facultados para intervenir la actividad de sus administrados cuando existiere perturbación o peligro de perturbación grave de la tranquilidad, seguridad y salubridad ciudadanas, a fin de restablecerlas o conservarlas (art. $1 . \circ$ número 1, del citado Reglamento de Servicios). En estos aspectos tiene especial relevancia la intervención municipal en materia de actividades molestas, insalubres, nocivas y peligrosas, reguladas de modo general en el Reglamento de 30 de noviembre de 1961. Vid. por todos, MARTIN MATEO, R.: Derecho ambiental, IEAL, Madrid, 1977, pág. 189 y sigs. 
crisis o emergencias que afecten a la salud o seguridad de los consumidores o usuarios ( 26 bis).

\section{INSTITUCIONALIZACIÓN JURÍDICA DE LA PARTICIPACIÓN DE LOS CONSUMIDORES Y USUARIOS}

La participación ciudadana en la gestión de funciones de interés general o público constituye, como es sabido, un principio de rango constitucional (27) que condiciona o, cuando menos, ha de influir de algún modo en la organización y actividad de las Administraciones públicas.

Ahora bien, además de las fórmulas de participación ciudadana propiamente dicha - strictu sensu- en el ejercicio de poderes o funciones administrativas de decisión y gestión, según la concepción elaborada por la doctrina clásica, que restringía a la Administración la gestión de los intereses públicos —cuya gestión por particulares se instrumentaba por técnicas jurídico-públicas, como la concesión de servicios públicos-, la demanda social de participación y colaboración ciudadana en funciones de interés general desborda en la actualidad el planteamiento clásico y ofrece nuevas fórmulas y cauces, ligados sobre todo al movimiento ciudadano, que se traduce en la institución de diversas entidades, asociaciones culturales, ecologistas, deportivas, etc.; esto es, una serie de mecanismos «sociales» que vienen a completar el clásico esquema o modelo de la Administración «autoritaria» e incluso de la democracia parlamentaria, para posibilitar la intervención de los administrados en la gestión de intereses colectivos, en materias que van desde el urba-

(26 bis) Véase el artículo 39.3, en relación con el 41.3 y 5 , de la Ley $26 / 84$. Asimismo las Ordenes de 15 de septiembre de 1982, 13 de diciembre de 1982 y 27 de marzo de 1984, sobre asistencia técnica y colaboración de la Administración Central con las Corporaciones Locales en materia de consumo.

(27) Cfr. los artículos 9.2, 23, 105.a) y 129 de la Constitución vigente. García DE ENTERRfA y FERNÁNDEZ RODRfGUEZ definen la participación del administrado en las funciones administrativas con referencia a la actuación ciudadana determinada por una apreciación libre del interés general, normalmente voluntaria, aunque eventualmente forzosa - siempre que ésta no defina una situación relativamente permanente y general, ni una ocupación estable- y no profesionalizada o retribuida dentro del sistema de intercambio de bienes y servicios (Curso de Derecho Administrativo, Civitas, II, pág. 76). Asimismo, sobre el significado, cauces y técnicas de participación ciudadana, vid. SáNCHEZ MoRón, M.: La participación del ciudadano en la Administración pública, CE Constitucionales, Madrid, 1980, y «Elementos de la participación ciudadana», Rev. Est. Vida Local, núm. 221 (enero-marzo 1984). En materia de urbanismo, mi estudio Elaboración y gestión en el planeamiento urbanístico (intervención de los particulares), Ed. Montecorvo, 1983, pág. 24 y sigs. 
nismo y el llamado en general «medio ambiente», hasta incluso las últimas fases del proceso productivo, con la entrega final de los diversos productos o bienes y servicios en el mercado.

La instrumentación del principio participativo se concreta sobre todo, en este aspecto, en una serie de fórmulas y técnicas jurídicas que tienen por objeto salvaguardar la sustantividad e independencia formal, jurídica y asociativa del movimiento ciudadano (28), por lo que los cauces mediante los que éste se institucionaliza no se instrumentan al modo clásico, con fórmulas de Derecho público, que presuponen exclusivas competencias administrativas - concesión, delegación, etc.-, sino con fórmulas jurídico-privadas, fundamentalmente de naturaleza asociativa, más respetuosas, formal y sustancialmente con la independencia de los ciudadanos, e imprescindible además si se tiene en cuenta que se trata de intervenir y controlar por parte de éstos no ya sólo la actuación de las empresas privadas, sino incluso de la Administración pública, en cuanto prestadora también de bienes y servicios cuya vital trascendencia para la vida social e individual, por patente, no requiere ser destacada.

No ha de extrañar por ello que se afirme, como hace PÉREZ Moreno, que la institucionalización de la participación de los consumidores debe estructurarse fuera de las Administraciones públicas y que debe admitirse la concurrencia de instituciones, sean en forma pública o privada (29).

No ha de sorprender por ello que la Ley 26/1984 trate de canalizar el ejercicio del derecho de participación en esta materia a través de asociaciones constituidas con arreglo a la Ley de Asociaciones (30), aun cuando también se consideran asociaciones de consumidores y usuarios las entidades constituidas por los mismos con arreglo a la legislación cooperativa (31), para realizar los fines que la propia Ley 26/1984 determina y entre los que cabe resaltar fundamentalmente los siguientes:

(28) Sobre el papel de las asociaciones ciudadanas como cauce participativo, vid. SÁNCHEZ MORÓN, M.: "Elementos de la participación ciudadana», cit. en nota anterior, Rev. Estudios de la Vida Local, núm. 221 (año 1984), pág. 44 y sigs.

(29) PÉrez MORENo, A.: «La institucionalización de la participación de los consumidores en el control de la calidad de los alimentos", Rev. Española de Derecho Administrativo, Civitas, núm. 31, pág. 649.

(30) Artículo 20.1, Ley 26/1984, de 19 de julio. Véase el artículo 22 de la Constitución, así como la Ley 191/1954, de 24 de diciembre, de Asociaciones, y el Decreto $1440 / 65$, de 20 de mayo.

(31) Artículo 20.2, Ley 26/1984, cit. Asimismo, la Ley 52/74, de 19 de diciembre, General de Cooperativas; Reglamento de 16-11-1975 y disposiciones concordantes. 
- La realización de funciones informativas y educativas de los consumidores y usuarios, en concurrencia con los que esta Ley atribuye a la Administración Pública. La competencia que se asigna a ésta, en sus diversas esferas, para informar a los consumidores y usuarios sobre los diferentes productos o servicios y para educar y facilitar el conocimiento sobre su adecuado uso, consumo o disfrute, mediante "oficinas de información de titularidad pública» (32), se completa con la posibilidad y facultad asimismo reconocida a las asociaciones de consumidores y usuarios para que, en ejercicio de la finalidad de defensa de los intereses de sus asociados, puedan organizar y realizar funciones análogas.

La existencia de oficinas de información de titularidad pública se entiende por ello legalmente -conforme determina la Ley 26/ 1984 , en su art. 14.2-, sin perjuicio de las que verifiquen las organizaciones de consumidores y usuarios, que podrán por tanto realizar tareas de educación y formación en materia de consumo.

- Se instrumenta, de otro lado, la participación de los consumidores y usuarios asociados por vía consultiva, en el ejercicio de poderes y competencias administrativas de dirección y gestión, ya que las asociaciones de aquéllos han de ser oídas, en consulta, en el procedimiento de elaboración de las disposiciones de carácter general relativas a materias que les afecten directamente (33).

En especial, según determina la propia Ley, en su artículo 22.2, será preceptiva la audiencia de dichas asociaciones en los siguientes casos: a) Reglamentos de aplicación de esta Ley. b) Reglamentaciones sobre productos o servicios de uso y consumo. c) Ordenación del mercado interior y disciplina del mercado. d) Precios y tarifas de servicios, en cuanto afecten directamente a los consumidores o usuarios, y se encuentren legalmente sujetos a control de las Administraciones públicas. e) Condiciones generales de los contratos de Empresas que prestan servicios públicos en régimen de monopolio, y f) En los casos en que una Ley así lo establezca.

- Por lo demás, ya en la actualidad los consumidores y usuarios se encuentran representados institucionalmente en diversos

(32) Véase los artículos 14 a 16 de la Ley $26 / 1984$, cit.

(33) Artículo 22.1, Ley 26/1984. En su artículo 2.'.1.e) determina que constituye derecho básico de los consumidores y usuarios la audiencia en consulta, la participación en el procedimiento de elaboración de las disposiciones generales que les afectan directamente y la representación de sus intereses, todo ello a través de las asociaciones, agrupaciones o confederaciones de consumidores y usuarios legalmente constituidas. 
órganos públicos y administrativos con competencias en materia de productos agrarios, pesca, seguros, precios, etc. (34). Supuestos éstos de participación orgánica en que se institucionaliza, por tanto, el principio que consideramos, dentro de la Administración pública.

Ahora bien, en el supuesto en que las asociaciones citadas se encuentren representadas en órganos colegiados que participen en la elaboración de las disposiciones a que se refiere el artículo 22.2 y 3 de la Ley 26/1984, se entenderá cumplido el trámite preceptivo de consulta a que se refieren (35).

Así pues, junto a las organizaciones y actuación de la Administración pública, se reconoce y estimula la intervención de los consumidores y usuarios mediante fórmulas asociativas, con las que se trata de encauzar e instrumentar la colaboración y participación social en las funciones de gestión informativa y educativa en la materia, sin perjuicio como es lógico de la potestad y responsabilidad propias de la Administración, y de la participación en su caso en diversos órganos administrativos.

Como órgano de representación y consulta a nivel nacional, la Ley 26/1984 prevé, en su artículo 22.5, que el Gobierno determinará la composición y funciones de un Consejo integrado por representantes de las asociaciones a que se refiere el artículo 20.

\section{FUNCIONES ADMINISTRATIVAS}

El deber - constitucional- de los poderes públicos de garantizar la defensa de los consumidores y usuarios - de sus legítimos intereses individuales y colectivos- requiere la realización de determinadas actuaciones, a desarrollar por las diversas Administracio-

(34) Véanse, entre otras:

- Ley $26 / 1968$, de 20 de junio, de creación del FORPA, artículo $5 .^{\circ}, m$ ).

- Ley 33/1980, de 21 de junio, de creación del Fondo de Regulación y Organización del Mercado de Productos de Pesca y cultivos marinos (FROM) (art. 5.1.ñ).

- RD 2695/77, de 28 de octubre, sobre normativa en materia de precios, modificado por el RD 816/82, de 26 de marzo, que regulan la representación en las Comisiones Provinciales de Precios, Juntas Locales de Precios y en la Junta Superior de Precios.

- RD 2335/83, de 4 de agosto. En la Junta Consultiva de Seguros (art. 22.2).

- Orden de 29 de marzo de 1978. En la Comisión Permanente de Consumo, antes denominada Comité de Dirección (art. 4. ${ }^{\circ}$ ).

- Por otra parte, el RD 1456/82, de 18 de junio, por el que se regula la Comisión Interministerial para la Ordenación Alimentaria, prevé la posibilidad de asistencia a sus reuniones de representantes de las asociaciones de consumidores.

(35) Artículo 22.4, Ley $26 / 1984$, de 19 de julio. 
nes públicas con competencia en la materia. Son numerosas y variadas las técnicas y medios de intervención administrativa que, en este aspecto, se hallan previstas en nuestro ordenamiento para proteger tales intereses, hasta el punto de que, como afirma BERMEJo VERA (36), su exposición sería de por sí inacabable, ya que desde el inicio de la década de los sesenta, existe toda una serie de instrumentos jurídicos de variado signo establecidos para corregir los desequilibrios que la liberalización económica comenzada entonces había de provocar. Pero se trataba de mecanismos administrativos concebidos ante todo desde la perspectiva de la intervención pública en la economía, aun cuando de forma más o menos indirecta entrañaran una función protectora de los administrados en su posición de consumidores.

Sin tratar de llevar a cabo una acabada exposición a este respecto de los diversos medios jurídicos y funciones administrativas, en el ordenamiento actual, parece, no obstante, conveniente sistematizar la diversidad existente reconduciéndola a una clasificación -ya clásica en nuestra doctrina administrativa - que distingue entre funciones de servicio público, policía y fomento, y que con éstas u otras análogas denominaciones o precisiones sustancialmente mantiene su virtualidad en la actual doctrina.

\section{Policfa administrativa}

A) Se incluyen en este aspecto, ante todo, las actuaciones de las Administraciones públicas que tienen por objeto la protección de los derechos básicos de los consumidores y usuarios contra los riesgos que puedan afectar su salud o seguridad. El artículo $3 .^{\circ}$ de la Ley 26/1984 establece por ello la prohibición de que los productos, actividades y servicios puestos en el mercado a disposición de los consumidores o usuarios no implicarán riesgos para su salud o seguridad, salvo los usual o reglamentariamente admitidos en condiciones normales y previsibles de utilización. Supuesto este último -excepcional- en que los posibles riesgos deben ser puestos en conocimiento previo de los consumidores y usuarios por medios apropiados, a través - según precisa el art. 13.f) de la propia Leyde instrucciones o indicaciones para su correcto uso o consumo, advertencias y riesgos previsibles.

(36) Estudio citado en nota 3, Rev. de Administración Pública, núm. 87, pág. 287. 
Se prevé asimismo (37), con la propia finalidad protectora de la salud y seguridad física de los consumidores, la reglamentación de las diversas operaciones de producción, transporte, comercialización y uso de bienes y servicios —en especial para los bienes de primera necesidad-, así como su vigilancia e inspección; estableciéndose de modo directo, ex lege, una serie de prohibiciones y deberes que, en todo caso, han de ser observados como garantía de la indicada finalidad, y entre los cuales destacan:

- La prohibición de utilizar cualquier aditivo que no figure expresamente citado en las listas positivas autorizadas y publicadas por el Ministerio de Sanidad y Consumo, y siempre teniendo en cuenta la forma, límites y condiciones que en aquéllas se establezcan (38).

- La exigencia de control de los productos tóxicos o venenosos, incluidos los resultantes de mezclas y otras manipulaciones industriales, de forma que pueda comprobarse con rapidez y eficacia su origen, distribución, destino y utilización (39).

- La prohibición de venta a domicilio de bebidas y alimentos, sin perjuicio del reparto, distribución o suministro de los adquiridos o encargados por los consumidores en establecimientos comerciales autorizados para la venta al público (40).

- El cumplimiento de la normativa que establezcan las Corporaciones Locales o, en su caso, las Comunidades Autónomas, sobre los casos, modalidades y condiciones en que podrá efectuarse la venta ambulante de bebidas $y$ alimentos.

- La prohibición de venta o suministro de alimentos envasados cuando no conste en los envases, etiquetas, rótulos, cierres o precintos, el número del Registro General Sanitario de Alimentos, en la forma reglamentariamente establecida (41).

(37) Véase el artículo $5^{\circ}$ de la Ley $26 / 1984$, de 19 de julio.

(38) Los aditivos alimentarios autorizados y las cantidades en que pueden ser utilizados para la fabricación de productos alimenticios se encuentran expresados en listas positivas publicadas por la Subsecretaría de Sanidad y Consumo o contenidas en las Reglamentaciones Técnico-Sanitarias. Véase el Real Decreto 3177/1983, de 16 de noviembre, por el que se aprueba la Reglamentación de aditivos alimentarios.

(39) Véase el Real Decreto 2621/1981, de 2 de octubre, sobre control de la actividad de obtención de aceites y grasas por esterificación, y la Orden de 6 de octubre de 1982 que desarrolla este Real Decreto.

(40) Reglamentariamente, se regulará el régimen de autorización de ventas directas a domicilio que vengan siendo tradicionalmente practicadas en determinadas zonas del territorio nacional (art. 5.2.d), in fine, Ley 26/1984, cit.).

(41) Véase el artículo 13.2 del Real Decreto 2058/82, de 12 de agosto, por el que 
- La obligación de retirar o suspender, mediante procedimientos eficaces, cualquier producto o servicio que no se ajuste a las condiciones y requisitos exigidos o que, por cualquier otra causa, suponga un riesgo previsible para la salud o seguridad de las personas (42).

- La prohibición de utilizar en la construcción de viviendas y locales de uso público materiales y demás elementos susceptibles de generar riesgos para la salud y seguridad de las personas (43).

- La obligación de que las especialidades farmacéuticas se presenten envasadas y cerradas con sistemas apropiados, aportando en sus envases o prospectos información sobre composición, indicaciones y efectos adversos, modo de empleo y caducidad, de suerte que los profesionales sanitarios sean convenientemente informados y se garantice la seguridad especialmente de la infancia, y se promueva la salud de los ciudadanos (44).

Por lo demás, la Ley $26 / 1984$, en su artículo $44^{\circ}$, remite a los Reglamentos reguladores de los diferentes productos, actividades o servicios (45) la determinación de su naturaleza, características, condiciones y requisitos relativos a las instalaciones, personal (46), procedimiento de fabricación y comercialización; etiquetado, pre-

se aprueba la Norma General de etiquetado, presentación y publicidad de los productos alimenticios envasados, y el Real Decreto 2825/81, de 27 de noviembre, sobre registro sanitario de alimentos.

(42) Sobre intervención cautelar y definitiva, véase artículo 14.3 y 4 del RD 1945/ 1983 , de 22 de junio, por el que se regulan las infracciones y sanciones en materia de defensa del consumidor y de la producción agroalimentaria.

(43) Las Normas Tecnológicas de la Edificación, el RD 2413/73, de 20 de septiembre, por el que se aprueba el Reglamento Electrotécnico para Baja Tensión, y sus Instrucciones complementarias, contienen exigencias de seguridad para los materiales, construcciones, instalaciones y aplicaciones que regulan. Véase también la Orden de 8 de mayo de 1984 por la que se dictan normas para la utilización de las espumas de urea-formol usadas como aislantes en la edificación.

(44) Véase el Decreto $3451 / 77$, de 1 de diciembre, y la Orden de 30 de mayo de 1980 sobre promoción, información y publicidad de especialidades farmacéuticas; la Orden de 15 de julio de 1982, por la que se regula el material de acondicionamiento de las especialidades farmacéuticas de uso humano no publicitarias; el RD 726/82, de 17 de marzo, sobre caducidad de especialidades farmacéuticas, y el RD 2829/77, de 6 de octubre, sobre estupefacientes.

(45) Numerosos productos de consumo se encuentran reglamentados por normas específicas. El Código Alimentario Español (Decreto 2484/67, de 21 de septiembre), las Reglamentaciones Técnico-Sanitarias y normas de calidad de productos alimenticios cubren un amplio espectro en el ámbito alimentario. Muchos productos industriales de consumo y algunos servicios cuentan, asimismo, con normas particulares que los regulan.

(46) Véase el RD 2505/83, de 4 de agosto, por el que se aprueba el Reglamento de Manipuladores de Alimentos. 
sentación y publicidad (47); métodos oficiales de análisis, tomas de muestras, control de calidad e inspección; garantías, responsabilidades, infracciones y sanciones, y régimen de autorización, registro y revisión.

B) En las limitaciones de policía administrativa también se incluye, con fines protectores del consumidor, la ordenación de precios y márgenes comerciales. En este aspecto, la política de precios es muy variada y dispersa, en función de la coyuntura económica. Además de la ordenación de precios de garantía o apoyo al productor -ante la debilidad o falta de la demanda, como ocurre por ejemplo con los precios de determinados productos agrícolas-, también existen limitaciones de precios en apoyo al consumidor (por ejemplo, del pan, según baremos en función del peso, arroz, leche, etc.), así como la regulación de márgenes comerciales y la intervención de tarifas de ciertos servicios o actividades (48).

La Ley 26/1984 incluye, entre las medidas de protección de los intereses económicos y sociales de los consumidores y usuarios, asimismo, diversos preceptos ordenados a asegurar la transparencia de los precios. Así, en aras del principio general de buena fe y justo equilibrio de las prestaciones, se prohíbe - «excluye» dice el artículo 10.1.c), de dicha Ley- incrementar el precio por servicios, accesorios, financiación, aplazamientos, recargos, indemnizaciones o penalizaciones que no correspondan a prestaciones adicionales, susceptibles de ser aceptados o rechazados en cada caso y expresados con la debida claridad y separación; así como también se prohíbe repercutir sobre el consumidor o usuario de fallos, defectos o errores administrativos, bancarios o de domiciliación de pagos, que no le sean directamente imputables, así como el coste de los

(47) Véase a este respecto el contenido de la nota 41. Asimismo, de modo general, el Estatuto de la Publicidad, aprobado por Ley 61/64, de 11 de junio. Vid. la Resolución de 31 de enero de 1984, aprobatoria de las normas de admisión de publicidad del ente público Radio Televisión Española.

(48) Véase el Real Decreto 2695/77, de 28 de octubre, sobre normativa de precios; el RD 816/82, de 26 de marzo, sobre composición y funcionamiento de la Junta Superior de Precios; la Orden de 17 de junio de 1983 por la que se da la relación de productos y servicios sometidos a régimen de precios autorizados y comunicados; la Orden de 5 de marzo de 1984, sobre márgenes comerciales; el RD 2226/77, de 27 de agosto, y la Orden de 30 de septiembre de 1977 que lo desarrolla, sobre autorizaciones de aumento de tarifas de servicios de competencia local.

Sobre la ordenación de precios, en general, vid. MANZANEDO Mateos, J., y otros: Curso de Derecho Administrativo económico, Instituto de Estudios de Administración Local, Madrid, 1970 (pág. 362 y sigs.), en donde se hace un interesante ensayo de sistematización en esta materia. Asimismo, vid. BERMejo VerA, J., cit. en nota 3. página 292. 
servicios que en su día y por un tiempo determinado se ofrecieron gratuitamente; y en la primera venta de viviendas, la estipulación de que el comprador ha de cargar con los gastos derivados de la preparación de la titulación, que por su naturaleza correspondan al vendedor (obra nueva, propiedad horizontal, hipotecas para financiar su construcción o su división y cancelación), entre otras determinaciones cuya infracción se sanciona legalmente con la nulidad de pleno derecho de las condiciones o estipulaciones que incumplan tales exigencias (49).

C) En lo que se refiere finalmente a las funciones de policía administrativa de carácter sancionador, situadas fundamentalmente en la denominada "disciplina del mercado» (50), ha de destacarse la especial atención que al régimen de infracciones $y$ sanciones administrativas en la materia dedica la Ley 26/1984, de 19 de julio, que tipifica, en su artículo 34, aunque con cierta ambigüedad, en bastantes de los supuestos de infracciones que regula, una serie de conductas, que incluso llega a generalizar respecto al «incumplimiento de los requisitos, obligaciones o prohibiciones establecidas en esta Ley y disposiciones que la desarrollan" (51).

Una consideración final. Aunque el artículo 32 de dicha Ley determina que la sanción administrativa de tales incumplimientos o infracciones se entiende "sin perjuicio de las responsabilidades civiles, penales o de otro orden que puedan concurrir", ha de afirmarse que, de conformidad con el principio "non bis in idem», implícito en la regulación contenida en el artículo 25 de la Constitución y recogido en la jurisprudencia del Tribunal Constitucional

(49) Vid, el artículo 10 de la Ley 26/1984, de 19 de julio. En su número 5 establece que los poderes públicos velarán por la exactitud en el peso y medida de los bienes y productos, la transparencia de los precios y las condiciones de los servicios postventa de los bienes duraderos.

La publicidad y marcado de precios en la venta al público de artículos al por menor y de los servicios aparece regulada por el Decreto 2807/72, de 15 de septiembre.

(50) Vid. Bermejo Vera, cit. en nota 3, pág. 292 y sigs. Asimismo en lo que se refiere en especial a este tema en materia de alimentación, RIVERo YSERN, E.: "La represión de las infracciones sanitarias en materia de alimentación", Libro homenaje a Garcia Trevijano, IEAL, Madrid, 1982, pág. 7766 y sigs.

(51) Véase el artículo 34 de la Ley 26/1984, de 19 de julio. Las infracciones tipificadas en dicho artículo se calificarán como leves, graves o muy graves, atendiendo a los criterios de riesgo, intencionalidad, beneficio obtenido y demás que establece el artículo 35 de la propia Ley. Infracciones cuya sanción regula, según los diversos tipos, con multas, la Ley, en su artículo 36 . Además, el artículo 38 prevé la posibilidad de imponer como sanción accesoria el decomiso de la mercancía adulterada, deteriorada, falsificada, fraudulenta, no identificada o que pueda entrañar riesgo para el consumidor. El RD 1945/83, de 22 de junio, regula las infracciones y sanciones en materia de defensa del consumidor y de la producción agroalimentaria. 
-Sentencias de 30 de enero y 8 de junio de 1981-, en ningún caso se producirá una doble sanción por los mismos hechos y en función de los mismos intereses públicos protegidos, si bien deberán exigirse las demás responsabilidades que se deduzcan de otros hechos 0 infracciones concurrentes (52).

\section{SERVICIO PÚBLICO}

La defensa de los consumidores y usuarios requiere de los poderes públicos no sólo de una acción protectora o de vigilancia y, en su caso, sancionadora, sino asimismo de prestación material de servicios para hacer posible la efectiva realización, ante todo, de los derechos constitucionales de información y educación de aquéllos (53) o, como de modo más detallado dice el artículo $2 .^{\circ}$ de la Ley 26/1984 -apartado 1.d) -, la información correcta sobre los diferentes productos o servicios y la educación y divulgación para facilitar el conocimiento sobre su adecuado uso, consumo o disfrute.

A partir de esta exigencia - deber- legal, impuesta a los productores de bienes y servicios, de dar una información «veraz, eficaz y suficiente sobre sus características esenciales" (54), se prevé la existencia de unas oficinas y servicios de información de titularidad pública - sin perjuicio de las propias de las organizaciones o asociaciones de consumidores y usuarios- que, además de las funciones de carácter general legalmente establecidas (55), para cumplir sus fines, podrán recabar a su vez información directamente de cualquier organismo público (56), así como facilitar los resultados de los estudios, ensayos, análisis o controles de calidad realizados en centros públicos o privados oficialmente reconocidos, cuyos resultados podrán ser reproducidos, en su caso, y previa audiencia de los productores implicados, en los medios de comunicación social (57).

(52) Artículo 33 de la Ley 26/1984, de 19 de julio. Sobre la suspensión del expediente administrativo por instrucción de causa penal, vid. el artículo 32.2 de la misma. En general, sobre la prohibición de doble sanción, administrativa y penal, por los mismos hechos, con referencia a las SS del TC citadas en el texto, vid. Garcf́a dE ENTERRfa, E.: "La incidencia de la Constitución sobre la potestad sancionadora de la Administración», REDA, núm. 29, pág. 359 y sigs.

(53) Véase el artículo 51.2 de la Constitución. En la doctrina, Cazorla Prieto,

L. M.: Comentarios..., cit. en nota 2, pág. 577 y sigs.

(54) Véase el artículo 13 de la Ley 26/1984, cit.

(55) Véase el artículo 14.1 de la Ley 26/1984.

(56) Véase el artículo 15 de la Ley $26 / 1984$.

(57) Véase el artículo 16 de la Ley 26/1984 citada. 
Los anteriores servicios informativos se complementan con otras actividades administrativas de carácter educativo $y$ divulgador, a través sobre todo de los medios de comunicación social de titularidad pública - televisión, radio, prensa-, con la publicación de espacios y programas no publicitarios (58), así como mediante la incorporación al sistema educativo general de los contenidos que en materia de consumo sean adecuados a la formación de los alumnos (59), con la finalidad, en cualquier caso, de viabilizar el cumplimiento de los objetivos de la educación y formación de los consumidores y usuarios que la Ley determina (60).

Para hacer frente, por otra parte, a las «situaciones de inferioridad, subordinación o indefensión» de los consumidores y usuarios (61), las Administraciones públicas competentes, además de las referidas oficinas y servicios informativos, han de realizar o promover, entre otras actividades (62), campañas de orientación del consumo, generales o selectivas, dirigidas a las zonas geográficas o grupos sociales más afectados, así como campañas o actuaciones programadas de control de calidad, con mención expresa de las personas, empresas o entidades que, previa y voluntariamente, se hayan incorporado.

Con independencia, en fin, del derecho de los consumidores o usuarios a ser indemnizados por los daños y perjuicios que, en su caso, les ocasione el consumo o uso de un bien o servicio, mediante el ejercicio de las acciones judiciales correspondientes ante la juris-

(58) Artículo 17 de la Ley $26 / 1984$, según el cual en tales espacios y programas, de acuerdo con su contenido y finalidad, se facilitará el acceso o participación de las asociaciones de consumidores y usuarios y demás grupos o sectores interesados, en la forma que reglamentariamente se determine por los poderes públicos competentes en la materia.

(59) Artículo 18.2, de la Ley 26/1984, citada.

(60) Objetivos que, según el artículo 18 de la Ley, son los de:

a) Promover la mayor libertad y racionalidad en el consumo de bienes y la utilización de servicios.

b) Facilitar la comprensión y utilización de la información a que se refiere el Capítulo IV (de la Ley: arts. 13 a 17).

c) Difundir el conocimiento de los derechos y deberes del consumidor o usuario y las formas más adecuadas para ejercerlos.

d) Fomentar la prevención de riesgos que puedan derivarse del consumo de productos o de la utilización de servicios.

e) Adecuar las pautas de consumo a una utilización racional de los recursos naturales.

f) Iniciar y potenciar la formación de los educadores en este campo.

(61) Véase el artículo 2, apartado 1.f) de la Ley 26/1984, citada, en relación con el artículo 23 de la misma.

(62) Véase el artículo 6, en relación con el 23, apartados b) y c) de la Ley 26/ 1984, cit. 
dicción ordinaria - civil o contencioso-administrativa, en su caso-, ha de destacarse la regulación de un sistema extrajudicial de carácter conciliatorio -análogo al sistema francés de «transacción" (63)-, previsto en el artículo 31 de la Ley que consideramos. Según este precepto, previa audiencia de los sectores interesados y de las Asociaciones de consumidores y usuarios, el Gobierno establecerá un sistema arbitral que, sin formalidades especiales, atienda y resuelva, con carácter vinculante y ejecutivo para ambas partes, las quejas o reclamaciones de los consumidores o usuarios, siempre que no concurra intoxicación, lesión o muerte, ni existan indicios racionales de delito, todo ello sin perjuicio de la protección administrativa y de la judicial, de acuerdo con lo establecido en el artículo 24 de la Constitución (64).

Se trata, pues, de un sistema de mediación o interposición de buenos oficios, en el que las dos partes - con los límites que el precepto señala- aceptan someterse, de modo voluntario, a la decisión del órgano de arbitraje, para reparar daños o perjuicios de pequeña importancia. La tutela judicial se completa, así, con un procedimiento arbitral, más sencillo y eficaz — por la celeridad y economía de la actuación-que permita resolver las quejas o reclamaciones de los consumidores o usuarios de una menor trascendencia objetiva para sus derechos o legítimos intereses.

\section{ACCIONES DE FOMENTO}

Supuesta la conveniencia pública de la acción protectora en la materia - que ya destaca el art. 51 de la Constitución al exigir de los poderes públicos una función de «fomento» de las organizaciones de consumidores, que como se ha indicado desarrollan ciertas funciones complementarias de la acción administrativa-, la Ley 26/84 prevé un conjunto de medidas que, en este sentido, tratan de

(63) Véase, BermeJo VerA, J., estudio cit. en nota 3, Rev de Administración Pública, núm. 87, pág. 296, donde cita la opinión de D. BaumanN, para quien el sistema de transacción resulta muy útil y eficaz, especialmente cuando las asociaciones de consumidores utilizan la ya citada acción civil en reparación de los daños y perjuicios causados.

(64) El sometimiento de las partes al sistema arbitral será voluntario y deberá constar expresamente por escrito (art. 31.2). Los órganos de arbitraje estarán integrados por representantes de los sectores interesados, de las organizaciones de consumidores y usuarios y de las Administraciones públicas dentro del ámbito de sus competencias (núm. 3). 
promover y estimular la actuación de tales organizaciones (65), entre cuyas medidas destaca ante todo la posibilidad de que las asociaciones de consumidores y usuarios sean «declaradas de utilidad pública»; declaración que, si bien no constituye en principio condición legal necesaria para obtener beneficios y ayudas públicas, subvenciones, premios, etc., ha de significar, sin embargo, como es lógico, un importante dato a tener en cuenta por la Administración, junto con otras circunstancias —objetivos, número de asociados, programas y actividades, etc.- para decidir de forma objetiva sobre el otorgamiento de la ayuda o beneficio de que se trate.

En especial, el artículo 23.f) de la citada Ley establece que los poderes públicos promoverán, entre otras acciones, la de otorgamiento de premios, menciones o recompensas a las personas, empresas o entidades que se distingan en el respeto, defensa y ayuda al consumidor, faciliten los controles de calidad y eviten obligaciones, trámites y costes innecesarios.

Ahora bien, para poder obtener cualquier beneficio, a este respecto, dichas asociaciones deberán figurar inscritas en un libro registro, que se llevará en el Ministerio de Sanidad y Consumo, y reunir las condiciones y requisitos que reglamentariamente se establezcan para cada tipo de beneficio (66).

Por lo demás, y aun cuando esta materia está pendiente de desarrollo reglamentario, es lógico suponer que los mecanismos y procedimientos para otorgar beneficios de tipo económico, especialmente subvenciones, habrán de responder a los principios de objetividad y de igualdad de oportunidades, que vinculan a la Administración pública, en todas sus esferas, y que hoy encuentran apoyo básico en la exigencia del artículo 103.1 del texto constitucional.

En lo que se refiere a las Corporaciones Locales, no cabe desconocer, en fin, la normativa reguladora de la llamada «acción de

(65) Véanse los artículos 39.2, 40 y 41.4 de la Ley $26 / 84$, de 19 de julio; preceptos que utilizan los términos de apoyar y subvencionar, promover, y el último de ellos de modo explícito el de "fomentar" las asociaciones de consumidores y usuarios.

(66) Artículo 20.3 de la Ley 26/84, que añade que en la determinación reglamentaria de las condiciones y requisitos se tendrán en cuenta, entre otros, criterios de implantación territorial, número de asociados y programas de actividades a desarrollar.

Existe un Censo de Organizaciones de Consumidores en el Instituto Nacional del Consumo (véase el art. $20^{\circ} .1$, apartados $h$ ) y $k$ ), de la Orden de 29 de marzo de 1978, y la Orden de 20 de julio de 1978).

No podrán disfrutar de beneficios reconocidos en la citada Ley las Asociaciones en que concurran alguna de las circunstancias que señala en su artículo 21 . 
fomento" y, en concreto, de las subvenciones (67), en cuanto establece una serie de criterios y exigencias bastante rigurosas, ya que, salvo en lo que respecta a la oportunidad o conveniencia - discrecional - de la concesión de beneficios de esta clase, el acto de otorgamiento de subvenciones tiene, sin embargo, carácter reglado y ha de ajustarse a un determinado procedimiento público, licitatorio, por regla general de concurso, con el que, además de acreditarse el cumplimiento de las circunstancias que la normativa de régimen local, citada en la nota anterior, determina (prohibición de subvenciones que obedezcan a simple liberalidad, límite del 50 por 100 del coste de la actividad a que se apliquen, etc.), se garantice la objetividad y generalidad -igualdad de oportunidades, interdicción de privilegios singulares- deseables, en base a los criterios fijados legalmente (68) y a las condiciones del clausulado o condicionado correspondiente.

Como en otras materias, la normativa de régimen local -respetuosa con tales principios- podría cumplir, por ello, una función referencial o paradigmática, habida cuenta de su contrastado valor, a tener en cuenta en el desarrollo reglamentario previsto en el artículo 20.3 de la Ley 26/1984; sin perjuicio, obvio es decirlo, de su carácter vinculante, hoy por hoy, para las entidades que engloba la Administración Local.

\section{CONCLUSIONES}

Como recapitulación final de lo expuesto cabe deducir las conclusiones siguientes.

Primera. La protección de los consumidores de bienes y usuarios de servicios, por los poderes públicos, que impone en su artículo 51 el vigente texto constitucional, comprende, entre otras posibilidades o actuaciones jurídicas, una serie de acciones administrativas que han de estar ordenadas en todo caso a satisfacer, por razones de interés público, derechos fundamentales de aquéllos, como el relativo a su salud y seguridad, y de modo instrumental

(67) Véanse los artículos 23 a 29 del Reglamento de Servicios de las Corporaciones Locales de 17 de junio de 1955. En la doctrina, por todos, vid. AlBI, F.: Tratado de los modos de gestión de las Corporaciones Locales, Ed. Aguilar, Madrid, 1960 (pág. 437 y sigs.). Más recientemente, FERnÁNDEZ FARRERES: La subvención, concepto y régimen jurídico, Madrid, 1983.

(68) Véase el artículo 20.3 , párrafo $29^{\circ}$, de la Ley $26 / 1984$, citado en la nota 66. 
los derechos de información y educación y el derecho a la participación en esta materia.

Segunda. La figura del consumidor y usuario se refiere, a estos efectos, jurídicamente, a cualquier persona, física o jurídica, de cualquier clase, siempre que aparezca, dentro del proceso de la actividad económica, en la posición de demanda para el consumo o uso inmediato, como destinatario final, de bienes o servicios.

Tercera. La actividad de la Administración pública orientada a la defensa del consumidor, ha de desenvolverse dentro del marco de nuestra "constitución económica» - arts. 38, 128 y.139, entre otros-, en cuyo modelo se articula la defensa de aquél, con un conjunto de acciones jurídicas, en diversos sectores de nuestro ordenamiento y también en el administrativo.

Cuarta. La actuación administrativa, a nivel estatal, se caracteriza en esta materia por la disgregación o dispersión orgánica, con atribución de funciones y competencias a diversos departamentos y organismos sectoriales, cuyas negativas consecuencias - descoordinación, acciones administrativas contradictorias- difícilmente puede superar la acción preferente del Ministerio de Sanidad y Consumo. Situación que impone reconsiderar la actual estructura administrativa, dispersa y disgregada, para adecuarla a los objetivos de la política del Estado -que básicamente determina el artículo 39 de la Ley 26/1984 y conforme a los principios básicos que, según el artículo 103 de la Constitución, han de inspirar a la Administración pública, también en la materia considerada.

Quinta. Las Comunidades Autónomas con competencias legales en la materia, aunque con diverso carácter y naturaleza según el alcance de la respectiva autonomía - que puede incluir poderes legislativos en las Comunidades con autonomía plena o de mera ejecución o gestión en las de autonomía gradual o diferida-, cuentan con la inicial ventaja de poder estructurar una organización administrativa de nueva planta que evite los defectos apuntados y el logro de una acción coordinada y unitaria al respecto.

Sexta. La Administración Local y, en especial, las Corporaciones municipales, tienen una misión de especial importancia a cumplir en la protección y defensa del consumidor, ya que para realizar las competencias que a este propósito tienen legalmente asignadas, cuentan no sólo con la circunstancia fáctica de su mayor inmediatividad o proximidad a los administrados —consumidores o usuarios-, sino también una larga tradición jurídica y administrativa 
de intervención, en especial en materia de subsistencias para asegurar el abasto de bienes de consumo de primera necesidad (control de calidades, de pesos y medidas, precios, etc.), lo que constituye una garantía para asegurar, a través de la organización municipal, la regularidad de todo el proceso en cualquier lugar de la geografía nacional.

Séptima. La instrumentación del principio participativo de los ciudadanos en la materia, se institucionaliza no sólo de forma orgánica, con la representación de los consumidores y usuarios en diversos órganos públicos, sino también desde fuera de las Administraciones Públicas, a través sobre todo de la constitución de asociaciones, que tienen no sólo la posibilidad de intervenir o participar por vía consultiva en determinadas actuaciones de aquéllas, sino también incluso para realizar ciertas funciones -informativas y educativas, etc.- en concurrencia con las que jurídicamente se atribuye a la Administración pública.

Octava. Las funciones y técnicas de intervención administrativa previstas en nuestro ordenamiento -que cabe reconducir y hemos reconducido al esquema clasificatorio ya clásico de la actividad administrativa, en nuestra doctrina: policía, servicio público y fomento-, ofrecen modalidades muy numerosas y variadas. De ellas, las medidas y acciones de policía administrativa ordenadas a la prevención y, en su caso, corrección, de riesgos o peligros para la salud o la seguridad de los consumidores o usuarios, y las dirigidas a la ordenación de los precios (mediante reglamentaciones, prohibiciones, inspecciones, sanciones, etc.), juegan un papel fundamental, imprescindible para asegurar la regularidad y normalidad del suministro de bienes de consumo y la prestación al público de servicios o actividades.

Novena. La efectividad de los derechos constitucionales de información y educación del consumidor requiere legalmente, asimismo, de una actividad de servicio público, a través sobre todo de la creación, organización y funcionamiento de unas oficinas de información de titularidad pública -en concurrencia con las propias de las organizaciones y asociaciones de consumidores- y la realización de otras actuaciones administrativas de carácter educativo, a través del sistema docente general, y divulgador, a través de los medios de comunicación social.

Décima. Las acciones administrativas de fomento o estímulo de la actividad de los particulares en la materia, mediante el otor- 
gamiento de beneficios jurídicos y económicos — subvenciones, premios, etc.- , han de instrumentarse de modo reglado. Sin perjuicio de la oportunidad o conveniencia de su concesión, el acto de otorgamiento de beneficios, en especial de subvenciones, deberá cumplir las condiciones de objetividad y de generalidad -igualdad de oportunidades- en todo caso deseables. 